\title{
The challenge of improving food supply
}

Food will become the new gold in a world where convergence of many events has affected the global food supply and the food market causing an upward spiralling of food prices. The world market prices of wheat, corn, rice and barley have all seen a sharp increase in price in recent times. This unprecedented price increase is a result of changes in both the supply and demand. The reasons for these changes are numerous. There have been shortfalls in grain production by the major producers mainly due to variability of weather. The recent extensive use of grains such as corn for biofuel production and the escalation of energy costs have contributed to the increase in the global food prices. In Asia, adverse weather conditions and the increased rice consumption both in China and India, have resulted in an increase in the price of rice in the region.

The crisis in global food supply has become one of the most important issues in world affairs today as it has severely impacted on the poor, especially those in the small and developing countries like Sri Lanka. To confront the unprecedented increase in world food prices the world needs to increase food production by at least $50 \%$. In the words of Ban ki-moon, UN Secretary General, "We have a historic opportunity to revitalize agriculture. The crisis also presents us with an opportunity to revisit past policies. While we must respond immediately to high food prices it is important that our long term focus is on improving food security. We must act for longer term resilience and contribute to global food security. Governments must tackle structural issues that impede agricultural development. Rural infrastructure needs should be addressed along with new financing mechanisms".

Policy makers along with scientists have to play a major role in the process of revitalizing agriculture to meet the challenge of increasing food production and make it available to people at an affordable price. Improving agricultural productivity of land that is already under cultivation which is degraded and infertile can be achieved through more effective soil and water management to make cultivation sustainable. This is all the more important in Sri Lanka where the extent of land available for agriculture is limited. The use of suitable seed and planting material, appropriate pest and disease management and selection of species resilient to poor weather conditions are also essential to improve agricultural productivity.

It is well known that about $40 \%$ of agricultural produce in the country perish before it reaches the consumer through damage during storage and transport. Suitable post harvest technologies and storage methods need to be practised to minimize these losses, which we can ill afford. Modern food processing technologies must be adopted for maximum use of agricultural produce to eliminate wastage. In addition, we must be prepared to face the adverse impacts of future climate change, which according to recent reports of the Intergovernmental Panel on Climate Change, is expected to affect agriculture in Asia through declining production and reduction in arable land area.

In this background the scientists have an obligation to make a committed and concerted effort to contribute to solve this problem the country is facing today. Research into new areas of technology to improve productivity and transferring the knowledge generated to the farmers need the highest priority. It is also the responsibility of the scientists to fully support the current national drive to bring under cultivation all arable land. Selection of crops suitable for specific areas giving due consideration for soil and weather conditions, strengthening the seed and other planting material production programmes as well as improving diary farming and fisheries should receive the attention of both scientists and policy makers.

It is important that knowledge generated by research scientists is transferred to the farmers for which effective extension mechanisms need to be in place. The agrarian infrastructure needs to be strengthened and modernized with information technology facilities to provide the farmer with the information and other inputs necessary to raise the level of agricultural productivity in the country. The expected goal of increased agricultural productivity will be achieved only with a collaborative team effort of policy makers, scientists, and extension and field staff along with the farming community. 